\title{
Association between estimated glomerular filtration rate at initiation of dialysis and mortality
}

\author{
William F. Clark MD, Yingbo Na MSc, Steven J. Rosansky MD, Jessica M. Sontrop PhD, Jennifer J. Macnab PhD, \\ Richard J. Glassock MD, Paul W. Eggers PhD, Kirby Jackson BSc, Louise Moist MD MSc
}

See related commentary by Stel and Jager, page 24

\begin{abstract}
Background: Recent studies have reported a trend toward earlier initiation of dialysis (i.e., at higher levels of glomerular filtration rate) and an association between early initiation and increased risk of death. We examined trends in initiation of hemodialysis within Canada and compared the risk of death between patients with early and late initiation of dialysis.
\end{abstract}

Methods: The analytic cohort consisted of 25910 patients at least 18 years of age who initiated hemodialysis, as identified from the Canadian Organ Replacement Register (20012007). We defined the initiation of dialysis as early if the estimated glomerular filtration rate was greater than $10.5 \mathrm{~mL} / \mathrm{min}$ per $1.73 \mathrm{~m}^{2}$. We fitted time-dependent proportional-hazards Cox models to compare the risk of death between patients with early and late initiation of dialysis.

Results: Between 2001 and 2007, mean estimated glomerular filtration rate at initiation of dialysis increased from 9.3 (standard deviation [SD] 5.2) to 10.2 (SD 7.1) $(p<0.001)$, and the proportion of early starts rose from $28 \%$ (95\% confidence interval $[\mathrm{Cl}] 27 \%-30 \%$ ) to
$36 \%$ (95\% Cl 34\%-37\%). Mean glomerular filtration rate was 15.5 (SD 7.7) $\mathrm{mL} / \mathrm{min}$ per 1.73 $\mathrm{m}^{2}$ among those with early initiation and 7.1 (SD 2.0) $\mathrm{mL} / \mathrm{min}$ per $1.73 \mathrm{~m}^{2}$ among those with late initiation. The unadjusted hazard ratio (HR) for mortality with early relative to late initiation was 1.48 (95\% Cl 1.43-1.54). The HR decreased to $1.18(95 \% \mathrm{Cl} 1.13-1.23)$ after adjustment for demographic characteristics, serum albumin, primary cause of end-stage renal disease, vascular access type, comorbidities, late referral and transplant status. The mortality differential between early and late initiation per 1000 patient-years narrowed after one year of follow-up, but never crossed and began widening again after 24 months of follow-up. The differences were significant at 6, 12, 30 and 36 months.

Interpretation: In Canada, dialysis is being initiated at increasingly higher levels of glomerular filtration rate. A higher glomerular filtration rate at initiation of dialysis is associated with an increased risk of death that is not fully explained by differences in baseline characteristics.
$\mathrm{E}$ xamination of dialysis registry data, both in the United States and Europe, has shown that this procedure is being initiated for patients with increasingly higher levels of estimated glomerular filtration rate. ${ }^{1-4}$ Although the indications for dialysis are often not recorded or not accessible for data-gathering, a large international survey of physicians in 2000 revealed that the two leading deter minants of early initiation were uremic signs and symptoms (38\%) and residual kidney function (32\%), with $90 \%$ of respondents indicating that initiating dialysis earlier (by 6-12 months) would give some major advantage in terms of outcomes. ${ }^{5}$ The timing of initiation of dialysis is based on clinical judgment and the interpretation of signs, symptoms and labora- tory test results, with possibly greater emphasis recently on estimated glomerular filtration rate following the introduction of national guidelines. ${ }^{6,7}$ These guidelines were influenced by studies conducted in the 1980s and 1990s, which suggested that late initiation was potentially harmful. ${ }^{8.9}$ In 2006, the US National Kidney Foundation suggested that initiation of dialysis be considered before stage 5 chronic kidney disease (estimated glomerular filtration rate $<15 \mathrm{~mL} / \mathrm{min}$ per $1.73 \mathrm{~m}^{2}$ ) if symptoms were related to both comorbidities and level of residual kidney function..$^{10}$ The guidelines were based on existing observational information and never advocated initiating dialysis at a specific value of estimated glomerular filtration rate. However, studies conducted since
Competing interests Richard Glassock has received consultancy fees and payment for development of education presentations from American Renal Associates. None declared for other authors.

This article has been peer reviewed.

Correspondence to: Dr. William F. Clark, William.Clark@lhsc.on.ca

CMAJ 2011. DOI:10.1503 /cmaj.100349 
2001 have shown no survival benefit with initiation of hemodialysis at higher values of estimated glomerular filtration rate. ${ }^{4,11-14}$

Using data from the Canadian Organ Replacement Register, we examined trends in the timing of hemodialysis initiation between 2001 and 2007, characterized patients with early and late initiation of dialysis and compared the risk of death between these groups over time while controlling for baseline imbalances. In this article, we discuss the confounding effects of selection, survivor, misclassification, lead-time and indication bias.

\section{Methods}

\section{Data source}

We obtained data from the Canadian Organ Replacement Register, a national registry maintained by the Canadian Institute for Health Information. ${ }^{15}$ This registry records the incidence, prevalence and outcome for all patients undergoing long-term dialysis and all solid organ transplant recipients in Canada. Dialysis service providers collect the data by completing survey forms for each patient at the initiation of dialysis and yearly thereafter, with status recorded as of Dec. 31. Patients provide their data voluntarily. We analyzed data for all adult patients (i.e., at least 18 years of age at the start of renal replacement therapy) with a recorded value for serum creatinine who received hemodialysis (in-centre or home) as their first form of renal replacement therapy between Jan. 1, 2001, and Dec. 31, 2007.

\section{Definitions}

We used the modification of diet in renal disease equation $\left(186 \times \mathrm{SCr}^{-1.154} \times \mathrm{age}^{-0.203} \times 0.742\right.$ [if female] $\times 1.21$ [if black] ${ }^{16}$ to determine estimated glomerular filtration rate. For this calculation, we used the last recorded serum creatinine $(\mathrm{SCr})$ measurement before initiation of dialysis. We defined the initiation of dialysis as early if estimated glomerular filtration rate was above 10.5 $\mathrm{mL} / \mathrm{min}$ per $1.73 \mathrm{~m}^{2} .{ }^{4,6,17}$ This threshold is greater than that in the updated guideline of the National Kidney Foundation Disease Outcomes Quality Initiative,${ }^{10}$ which recommends initiating dialysis at estimated glomerular filtration rate of 10 $\mathrm{mL} / \mathrm{min}$ per $1.73 \mathrm{~m}^{2}$. We estimated the burden of comorbid disease using the end-stage renal disease comorbidity index..$^{18}$ Vascular access for initial dialysis was by arteriovenous fistula, arteriovenous graft or central venous catheter. We documented the presence or absence of coronary artery disease (angina, myocardial infarction or coronary artery bypass surgery), peripheral vas- cular disease, hypertension, diabetes mellitus (types 1 and 2) and cerebrovascular disease in three categories: yes, no and unknown. The categories for "no" and "unknown" constituted the reference group. We defined late referral as the patient having first seen a nephrologist within three months before initiation of dialysis, with albumin being the last recorded measurement before initiation of dialysis.

\section{Statistical analysis}

We followed cohort members from initiation of dialysis until death, loss to follow-up or the end of the observation period (Dec. 31, 2007). We compared patients' characteristics using $\chi^{2}$, Wilcoxon or $t$ tests, as appropriate. We estimated hazard ratios (HRs) and 95\% confidence intervals (CIs) from time-dependent proportionalhazards Cox models. We adjusted the models for the following variables: age, sex, ethnicity, serum albumin, primary cause of end-stage renal disease, type of vascular access (arteriovenous fistula and arteriovenous graft combined v. central venous catheter), end-stage renal disease comorbidity index, late referral and transplant status. Change in treatment modality from dialysis to transplant was included as a time-varying covariate. We used Poisson regression to compare mortality rates (expressed per 1000 patientyears on dialysis) between early and late initiation in six-month intervals over three years. We compared cause-specific mortality rates for patients with early and late initiation of dialysis using the Cochran-Mantel-Haenszel test for general association. We report the data as means and standard deviations.

\section{Results}

\section{Study sample}

We identified 29178 potentially eligible patients who initiated dialysis between 2001 and 2007. We excluded 3268 patients (11.2\%) because serum creatinine values were missing. The study sample therefore consisted of 25910 adult patients. The median follow-up time was 2.3 years. Of these patients, 8441 (32.6\%) had early initiation of dialysis, at estimated glomerular filtration rate above $10.5 \mathrm{~mL} / \mathrm{min}$ per $1.73 \mathrm{~m}^{2}$. The remainder (17 469 or $67.4 \%$ ) had late initiation of dialysis, at estimated glomerular filtration rate of $10.5 \mathrm{~mL} / \mathrm{min}$ per $1.73 \mathrm{~m}^{2}$ or less. Mean estimated glomerular filtration rate was 15.5 (standard deviation [SD] 7.7) $\mathrm{mL} / \mathrm{min}$ per $1.73 \mathrm{~m}^{2}$ among those with early initiation and 7.1 (SD 2.0) $\mathrm{mL} / \mathrm{min}$ per $1.73 \mathrm{~m}^{2}$ among those with late initiation. The group with early initiation appeared less healthy, since most potential risk 
factors for death were more common in this group (Table 1), the exception being late referral, which was more common among those with late initiation of dialysis. Patients with early initiation were older, more likely to be male and more likely to be white. In addition, the prevalence of diabetes was higher, the prevalence of glomerulonephritis and renal transplantation was lower, and the end-stage renal disease comorbidity index was greater.

\section{Trends in initiation of dialysis, 2001-2007}

Between 2001 and 2007, the mean estimated glomerular filtration rate at the time of initiation of dialysis increased by about $10 \%$, from 9.3 (SD 5.2) to 10.2 (SD 7.1) $\mathrm{mL} / \mathrm{min}$ per $1.73 \mathrm{~m}^{2}(p<$ 0.001 for trend), and nearly one-third of the cohort underwent early initiation, at estimated glomerular filtration rate above $10.5 \mathrm{~mL} / \mathrm{min}$ per $1.73 \mathrm{~m}^{2}$. During this period, the proportion of patients with early initiation of dialysis rose from $28 \%$ (95\% CI $27 \%-30 \%$ ) to $36 \%$ (95\% CI $34 \%-$ 37\%) (Appendix 1, available at www.cmaj.ca/cgi /content/full/cmaj.100349/DC1).

\section{Trends in mortality in relation to initiation of dialysis}

Kaplan-Meier survival curves for early and late initiation showed that the difference in survival was attenuated after adjustment for baseline characteristics (Appendix 2, available at www.cmaj .ca/cgi/content/full/cmaj.100349/DC1). Nonetheless, a significant difference remained after three years of follow-up. Similarly, after adjustment for differences in demographic characteristics, serum albumin, renal diagnosis, type of vascular access, comorbidities, late referral and transplant status, the HR for mortality decreased from 1.48 (95\% CI $1.43-1.54$ ) to 1.18 (95\% CI 1.13-1.23), but remained statistically significant (Table 2). The adjusted mortality differential between patients with early and late initiation of dialysis narrowed after one year of follow-up, but the mortality rates never converged, and the differential began to widen again after two years (Appendix 3, available at www.cmaj.ca/cgi/content/full/cmaj $.100349 / \mathrm{DC} 1)$. The differences were significant at $6,12,30$ and 36 months. After three years of follow-up, there were 27 more deaths per 1000 patient-years in the group with early initiation relative to the group with late initiation.

\section{Cause-specific mortality}

Cause of death was available for $8910(73.6 \%)$ of the 12111 patients who died (Table 3). No significant difference in cause-specific mortality was evident between patients with early and late initiation of hemodialysis $(p=0.13)$.
Table 1: Baseline characteristics of 25910 adult patients for whom hemodialysis was initiated between 2001 and 2007 in Canada

\begin{tabular}{|c|c|c|c|}
\hline \multirow[b]{2}{*}{ Characteristic } & \multicolumn{2}{|c|}{$\begin{array}{l}\text { Stage of initiation; } \\
\text { no. }(\%) \text { of patients* }\end{array}$} & \multirow[b]{2}{*}{$p$ value } \\
\hline & $\begin{array}{c}\text { Early } \dagger \\
n=8441\end{array}$ & $\begin{array}{c}\text { Late } \neq \\
n=17469\end{array}$ & \\
\hline Age, yr, mean (SD) & $67.5(14.0)$ & $63.7(15.2)$ & $<0.001$ \\
\hline Sex, male & $5656(67.0)$ & $9853(56.4)$ & $<0.001$ \\
\hline Ethnicity & & & $<0.001$ \\
\hline Asian & $329 \quad(3.9)$ & 1013 & \\
\hline Black & $253 \quad(3.0)$ & $542 \quad(3.1)$ & \\
\hline White & 6576 (77.9) & 12979 (74.3) & \\
\hline Other & $726 \quad(8.6)$ & 2079 (11.9) & \\
\hline Unknown & $557 \quad(6.6)$ & $856 \quad(4.9)$ & \\
\hline \multicolumn{4}{|l|}{$\begin{array}{l}\text { Estimated GFR, } \\
\mathrm{mL} / \mathrm{min} \text { per } 1.73 \mathrm{~m}^{2}\end{array}$} \\
\hline Mean (SD) & $15.5 \quad(7.7)$ & $7.1 \quad(2.0)$ & $<0.001$ \\
\hline Median (IQR) & $13.4 \quad(3.8)$ & $7.2 \quad(3.0)$ & $<0.001$ \\
\hline \multicolumn{4}{|l|}{$\begin{array}{l}\text { Serum albumin before } \\
\text { dialysis, } \mathrm{g} / \mathrm{L}\end{array}$} \\
\hline Mean (SD) & $32.0 \quad(7.0)$ & $31.9 \quad(6.8)$ & 0.29 \\
\hline Median (IQR) & $33.0 \quad(9.0)$ & $32.0 \quad(9.0)$ & 0.033 \\
\hline $\begin{array}{l}\text { Primary cause of renal } \\
\text { disease }\end{array}$ & & & 0.018 \\
\hline Glomerulonephritis & $608 \quad(7.2)$ & 2247 (12.9) & \\
\hline Diabetes mellitus & 3427 (40.6) & 5917 (33.9) & \\
\hline Renal vascular disease & $1865(22.1)$ & 3364 (19.3) & \\
\hline Other & $1427(16.9)$ & 3765 (21.6) & \\
\hline $\begin{array}{l}\text { Cause uncertain or } \\
\text { unknown }\end{array}$ & $1114(13.2)$ & $2176(12.5)$ & \\
\hline Late referral & 2807 (35.9) & 6585 (40.6) & $<0.001$ \\
\hline $\begin{array}{l}\text { Dialysis access via } \\
\text { arteriovenous fistula or } \\
\text { arteriorvenous graft }\end{array}$ & $1774(22.3)$ & 3799 (22.7) & 0.46 \\
\hline $\begin{array}{l}\text { Comorbidity index for end- } \\
\text { stage renal disease, mean (SD) }\end{array}$ & $2.6 \quad(2.3)$ & $1.9 \quad(2.1)$ & $<0.001$ \\
\hline \multicolumn{4}{|l|}{ Comorbidities } \\
\hline Coronary artery disease & 3790 (44.9) & 5468 (31.3) & $<0.001$ \\
\hline Peripheral vascular disease & $2195(26.0)$ & $3144(18.0)$ & $<0.001$ \\
\hline Cerebrovascular disease & $1418(16.8)$ & 2306 (13.2) & $<0.001$ \\
\hline Diabetes mellitus & $4448(52.7)$ & 7577 (43.4) & $<0.001$ \\
\hline Hypertension & $6930(82.1)$ & 14377 (82.3) & 0.65 \\
\hline Pulmonary edema & $2760(32.7)$ & $4193(24.0)$ & $<0.001$ \\
\hline Lung disease & $1418(16.8)$ & $2184(12.5)$ & $<0.001$ \\
\hline $\begin{array}{l}\text { Other malignancy or serious } \\
\text { disease }\end{array}$ & $2026(24.0)$ & $3529(20.2)$ & $<0.001$ \\
\hline Transplant§ & $490 \quad(5.8)$ & $2166(12.4)$ & $<0.001$ \\
\hline
\end{tabular}

Note: GFR = glomerular filtation rate, IQR = interquartile range, SD = standard deviation. *Unless stated otherwise.

tEarly initiation was defined as initiation with estimated GFR $>10.5 \mathrm{~mL} / \mathrm{min}$ per $1.73 \mathrm{~m}^{2}$ fLate initiation was defined as initiation with estimated GFR $\leq 10.5 \mathrm{~mL} / \mathrm{min}$ per $1.73 \mathrm{~m}^{2}$ $\S$ Transplantation was performed during follow-up, after initiation of dialysis. 


\section{Interpretation}

The results of this study, which arise from the publicly funded national health care system in Canada, confirm analyses of renal registries in the United States ${ }^{1,12,13}$ the United Kingdom ${ }^{11}$ and Europe. ${ }^{4}$ There has been a consistent lack of benefit with early initiation of dialysis (as defined by estimated glomerular filtration rate)

Table 2: Hazard ratios for mortality among 25910 adult patients for whom hemodialysis was initiated between 2001 and 2007 in Canada

\begin{tabular}{|c|c|c|}
\hline \multirow[b]{2}{*}{ Predictor } & \multicolumn{2}{|c|}{ HR for mortality* $(95 \% \mathrm{Cl})$} \\
\hline & Unadjusted & Adjusted $\dagger$ \\
\hline Early initiation of dialysisł & $1.48(1.43-1.54)$ & $1.18(1.13-1.23)$ \\
\hline \multicolumn{3}{|l|}{ Demographic characteristics } \\
\hline Age (per 10-year increment) & $1.43(1.41-1.45)$ & $1.41(1.39-1.43)$ \\
\hline Male sex & $1.04(1.00-1.07)$ & $1.08(1.04-1.12)$ \\
\hline \multicolumn{3}{|l|}{ Ethnicity (reference white) } \\
\hline Asian & $0.62(0.57-0.68)$ & $0.66(0.60-0.73)$ \\
\hline Black & $0.43(0.38-0.49)$ & $0.52(0.45-0.60)$ \\
\hline Other & $0.69(0.65-0.73)$ & $0.62(0.53-0.72)$ \\
\hline Unknown & $1.16(1.09-1.24)$ & $1.16(1.07-1.26)$ \\
\hline \multicolumn{3}{|l|}{ Clinical characteristics } \\
\hline $\begin{array}{l}\text { Serum albumin before dialysis } \\
\text { (per } 1 \mathrm{~g} / \mathrm{dL} \text { increase) }\end{array}$ & $0.78(0.76-0.81)$ & $0.78(0.75-0.80)$ \\
\hline \multicolumn{3}{|l|}{$\begin{array}{l}\text { Renal diagnosis (reference } \\
\text { glomerulonephritis) }\end{array}$} \\
\hline Diabetes mellitus & $1.77(1.64-1.89)$ & $1.48(1.37-1.60)$ \\
\hline Renal vascular disease & $2.02(1.88-2.18)$ & $1.26(1.16-1.37)$ \\
\hline Unknown & $2.07(1.91-2.23)$ & $1.49(1.37-1.64)$ \\
\hline Other & $1.70(1.57-1.83)$ & $1.55(1.42-1.69)$ \\
\hline $\begin{array}{l}\text { Access type (arteriovenous } \\
\text { fistula or arteriovenous graft v. } \\
\text { central venous access) }\end{array}$ & $0.62(0.59-0.65)$ & $0.73(0.69-0.77)$ \\
\hline \multicolumn{3}{|l|}{$\begin{array}{l}\text { Comorbidity index for end-stage } \\
\text { renal disease (reference } 0 \text { ) }\end{array}$} \\
\hline 1 & $1.55(1.44-1.67)$ & $1.35(1.24-1.47)$ \\
\hline 2 & $1.34(1.28-1.41)$ & $1.20(1.13-1.27)$ \\
\hline 3 & $1.83(1.72-1.94)$ & $1.42(1.32-1.52)$ \\
\hline 4 & $1.82(1.72-1.92)$ & $1.44(1.34-1.53)$ \\
\hline 5 & $2.26(2.13-2.41)$ & $1.74(1.62-1.87)$ \\
\hline 6 & $2.34(2.17-2.52)$ & $1.86(1.71-2.03)$ \\
\hline$\geq 7$ & $2.66(2.47-2.87)$ & $1.92(1.76-2.10)$ \\
\hline Late referral & $1.29(1.25-1.34)$ & $1.11(1.07-1.16)$ \\
\hline Transplant§ & $0.07(0.06-0.09)$ & $0.15(0.12-0.19)$ \\
\hline \multicolumn{3}{|c|}{$\begin{array}{l}\text { Note: } \mathrm{Cl}=\text { confidence interval, } \mathrm{HR}=\text { hazard ratio. } \\
{ }^{*} \text { Hazard ratios were estimated from a time-dependent Cox proportional-hazards regression. } \\
\text { †Adjusted for age, sex, ethnicity, serum albumin, renal diagnosis, vascular access type, } \\
\text { comorbidity index for end-stage renal disease, late referral and transplant status, as } \\
\text { appropriate. } \\
\text { †Early initiation of dialysis was defined as estimated glomerular filtration rate }>10.5 \mathrm{~mL} / \mathrm{min} \\
\text { per } 1.73 \mathrm{~m}^{2} \text {. } \\
\S \text { Transplant status was modelled as a time-varying effect. }\end{array}$} \\
\hline
\end{tabular}

across study populations from heterogeneous health care delivery systems, which may differ in terms of standard of care or financial incentives for initiation of dialysis. This lack of benefit suggests that the results are not driven by a particular model of health care and are robust to differences among renal registries in terms of patient characteristics, procedures for collecting data and methods of ascertaining comorbidity.

Until the recent publication of the Initiating Dialysis Early and Late (IDEAL) trial, a randomized controlled trial that showed no benefit of early initiation of dialysis,,$^{14}$ evidence on the ideal timing of dialysis initiation came solely from observational studies. Although much of that early observational research suggested a benefit with early initiation, ${ }^{8,9}$ recent studies have not. ${ }^{1,411-13,19}$ The apparent survival advantage of early initiation in the previous observational studies may be explained by greater rates of late referral among patients with late initiation, with patients for whom dialysis was initiated early being more likely to have benefited from predialysis care and being more likely to have a fistula. ${ }^{20}$ As well, the early studies failed to account for lead-time bias, which favours survival in the early-initiation group, as shown by Traynor and associates. ${ }^{11}$ Lead-time bias is a phenomenon whereby patients entering a study earlier in their disease process (e.g., at higher residual renal function) will appear to survive longer than those who enter at a later stage in their disease. ${ }^{11}$ Our analysis

Table 3: Cause of death in 12111 adult patients for whom hemodialysis was initiated between 2001 and 2007 in Canada*

\begin{tabular}{|c|c|c|}
\hline \multirow[b]{2}{*}{ Cause of death } & \multicolumn{2}{|c|}{$\begin{array}{l}\text { Stage of initiation; } \\
\text { no. }(\%) \text { of patients }\end{array}$} \\
\hline & $\begin{array}{c}\text { Early } \dagger \\
n=4498\end{array}$ & $\begin{array}{l}\text { Late } \neq \\
n=7613\end{array}$ \\
\hline Cardiac & $1120(24.9)$ & $1804(23.7)$ \\
\hline Infection & $400 \quad(8.9)$ & $624 \quad(8.2)$ \\
\hline Vascular & $198 \quad(4.4)$ & $396 \quad(5.2)$ \\
\hline Gastrointestinal & $121 \quad(2.7)$ & $221 \quad(2.9)$ \\
\hline Respiratory & $58 \quad(1.3)$ & $99 \quad(1.3)$ \\
\hline Social§ & $652(14.5)$ & 1112 (14.6) \\
\hline Other & $742(16.5)$ & 1363 (17.9) \\
\hline $\begin{array}{l}\text { Uncertain or not } \\
\text { determined }\end{array}$ & $1207(26.8)$ & 1994 (26.2) \\
\hline \multicolumn{3}{|c|}{$\begin{array}{l}\text { *Stage of initiation was not significantly associated with } \\
\text { cause of death }(p=0.13) \text {. } \\
\text { tEarly initiation was defined as estimated glomerular } \\
\text { filtration rate }>10.5 \mathrm{~mL} / \mathrm{min} \text { per } 1.73 \mathrm{~m}^{2} \text {. } \\
\text { fLate initiation was defined as estimated glomerular } \\
\text { filtration rate } \leq 10.5 \mathrm{~mL} / \mathrm{min} \text { per } 1.73 \mathrm{~m}^{2} \text {. } \\
\text { \$Refusal of further treatment or cessation of therapy for } \\
\text { any other reason. }\end{array}$} \\
\hline
\end{tabular}


has shown a clear survival benefit for initiating dialysis late without correction of the data for lead-time bias. Making that correction would produce an even greater survival advantage.

Whereas lead-time bias favours survival in the early-initiation group, several other biases favour survival in the late-initiation group, including selection, immortal time, misclassification, indication and survivor biases.

More specifically, patients who appear at risk for malnutrition may be more likely to be selected for early initiation of dialysis. In this study and others, ${ }^{21,22}$ patients with early initiation of dialysis differed from those with late initiation on important prognostic indicators. Although adjusting for imbalances in baseline characteristics attenuated the association between early initiation and mortality, the association remained significant. Furthermore, sensitivity analyses using propensity-score matching produced higher HRs (Appendix 4, available at www.cmaj .ca/cgi/content/full/cmaj.100349/DC1), which suggests that the increased mortality rate among patients with early initiation of dialysis is not completely explained by the presence of sicker patients in this group. This finding is consistent with those reported by Beddhu and colleagues. ${ }^{12}$

Also important to consider is the potential for the immortal time bias, which can occur when selection bias combines with survivor effects. ${ }^{23}$ In this context, the immortal time bias favours survival among patients with late initiation of dialysis, who must have survived long enough for their estimated glomerular filtration rate to fall below $10.5 \mathrm{~mL} / \mathrm{min}$ per $1.73 \mathrm{~m}^{2}$. The resulting "survival of the fittest" effect in the lateinitiation group could produce a healthier, more robust cohort at lower risk of dying. However, our results are consistent with those of Traynor and associates, ${ }_{11}^{11}$ who corrected for this type of bias by starting follow-up at a common level of renal function, before initiation of dialysis. Even after accounting for additional deaths in the interval between entry into the study and initiation of dialysis, no significant benefit for early initiation was evident.

Finally, misclassifying patients as having early initiation is more likely to occur among sick, frail or elderly patients and those with diabetes, since they are at greater risk of sarcopenia or protein inanition, with resultant lower levels of serum creatinine and falsely high levels of estimated glomerular filtration rate. Misclassification bias may be greater when the modification of diet in renal disease formula is used to calculate glomerular filtration rate, rather than calculating creatinine and urea clearance. ${ }^{12,24} \mathrm{We}$ conducted our analyses using both glomerular filtration rate estimated from the modification of diet in renal disease equation and serum creatinine clearance as a continuous variable, obtaining the same results (Appendix 5, available at www.cmaj.ca /cgi/content/full/cmaj.100349/DC1). However, we were unable to measure creatinine clearance directly and therefore cannot exclude misclassification bias due to differences in muscle mass between the groups.

With the exception of lead-time bias, imbalances in risk factors at baseline coupled with the potential for misclassification and immortal time biases favour survival in the late-initiation group. Although adjustment for baseline imbalances lessened the mortality differential, a significant difference persisted. The remaining mortality differential between patients with early and late initiation of dialysis would be expected to converge over time as the sicker patients (predominantly allocated or misclassified into the early-initiation group) die, leaving groups that share similar mortality risks. Our data did show an initial trend toward convergence after one year of follow-up (Appendix 3, available at www.cmaj .ca/cgi/content/full/cmaj.100349/DC1), but the differential significantly widened again after two years, which suggests that mortality differences may be influenced by competing causes, with a varying time effect.

In contrast to the results of the IDEAL trial, ${ }^{14}$ which showed no benefit of early initiation, our study suggests a possible harmful effect. This difference may result from incomplete statistical control for differences in baseline risk factors between patients with early and late initiation of dialysis, but it may also reflect important differences between the study samples. Whereas our analysis of 25910 patients captured more than $90 \%$ of all patients in Canada for whom hemodialysis was initiated during the study period, the IDEAL trial $(n=871)$ captured only $10 \%$ of patients in the study country of Australia. More importantly, the mean estimated glomerular filtration rate among patients with early initiation, as determined by the modification of diet in renal disease equation, was markedly higher in our study than in the IDEAL trial $(15.5$ v. 9.0 $\mathrm{mL} / \mathrm{min}$ per $1.73 \mathrm{~m}^{2}$ ) and there was a greater difference between the groups with early and late initiation ( $8.4 \mathrm{v} .1 .8 \mathrm{~mL} / \mathrm{min}$ per $\left.1.73 \mathrm{~m}^{2}\right)$.

A nonsignificant increase in cardiovascular deaths in the early-initiation group was observed in both this study and the IDEAL trial. ${ }^{14}$ Sudden cardiac death is the most common cause of death among patients undergoing hemodialysis, ${ }^{25-27}$ and some researchers have suggested that sudden cardiac death may be precipitated by the dialysis procedure itself. ${ }^{28,29}$ Patients with higher residual renal 
function have less intradialytic weight gain because clearance is preserved, and they may be at greater risk for hypotension because of ultrafiltration from the dialysis. The increased risk of hypotension with its attendant effect on cardiac ischemia, combined with myocardial stunning, ${ }^{28,30}$ could contribute to increased mortality among patients with initiation of dialysis at higher levels of estimated glomerular filtration rate. Consistent with this hypothesis, Termorshuizen and coworkers $^{2}$ found that excess ultrafiltration in relation to intradialytic weight gain was associated with increased mortality.

A recent analysis of data from the Canadian Organ Replacement Register showed a sharp increase in initiation of dialysis among those older than 75 years for the period 1998 to 2001 . The higher rate was maintained until 2005, after which it declined slightly, from 760 per million in 2005 to 708 per million in 2008. ${ }^{15}$ Concern about a rising tide of early dialysis initiation may have encouraged interest in maximizing conservative therapy for elderly patients. Importantly, initiating longterm hemodialysis in elderly patients with ischemic heart disease or multiple comorbidities does not appear to confer a survival benefit over conservative treatment. ${ }^{21,31}$ Moreover, the potential decrease in quality of life, loss of independence and functional decline that may follow initiation of dialysis at higher levels of estimated glomerular filtration rate are important to consider. Recent studies have shown that early initiation of dialysis does not improve health-related quality of life and may in fact worsen it. ${ }^{3233} \mathrm{~A}$ small prospective study evaluating initiation of dialysis at estimated glomerular filtration rate below $6 \mathrm{~mL} / \mathrm{min}$ per $1.73 \mathrm{~m}^{2}$ in a cohort of patients with low comorbidity revealed a significant gain in the amount of time free from dialysis, with good quality-of-life scores and major economic savings. ${ }^{34}$

\section{Limitations}

In addition to the biases inherent to observational data, this study had limitations associated with the use of registry data. Although $92.3 \%$ of the patients undergoing dialysis in Canada were captured in the Canadian Organ Replacement Register, overreporting may have resulted from the capture of patients receiving dialysis for acute renal failure in the comparison data source ${ }^{35} \mathrm{~A}$ major limitation of this and many other studies is potential confounding by indication because of a lack of accurate records of signs and symptoms of uremia that are reported to be major determinants of initiation of dialysis. ${ }^{1-5}$ It is impossible to completely eliminate bias by indication; however, any residual confounding not captured by our methods of adjustment would have to be substantial to mask a benefit of early initiation. In contrast to previous studies, we employed several different analytical techniques (Kaplan-Meier analysis, six-month by three-year mortality analysis, multivariable Cox proportional-hazards regression and analysis of propensity scores) to tease apart and better understand the relation between timing of dialysis initiation and mortality risk.

\section{Conclusions}

The consistent absence of a survival benefit with early initiation of dialysis across a variety of study designs, populations and health care delivery systems supports the conclusion that early initiation confers no survival benefit and argues against pre-emptive initiation of dialysis in asymptomatic patients. In contrast to early initiation of dialysis, early referral to a nephrologist is consistently associated with better survival. Further research is needed to determine the objective signs, symptoms and laboratory test results associated with increased mortality and decreased quality of life among patients with advanced renal failure. Rigorous comparative testing of these indicators in relation to the optimal timing of initiation of dialysis, survival, quality of life and cost effectiveness is necessary to inform future evidence-based national guidelines on this subject.

\section{References}

1. Rosansky SJ, Clark WF, Eggers P, et al. Initiation of dialysis at higher GFRs: Is the apparent rising tide of early dialysis harmful or helpful? Kidney Int 2009;76:257-61.

2. Termorshuizen F, Korevaar JC, Dekker FW, et al. Time trends in initiation and dose of dialysis in end-stage renal disease patients in the Netherlands. Nephrol Dial Transplant 2003;18: $552-8$

3. Kurella M, Covinsky KE, Collins AJ, et al. Octogenarians and nonagenarians starting dialysis in the United States. Ann Intern Med 2007; 146:177-83.

4. Stel VS, Dekker FW, Ansell D, et al. Residual renal function at the start of dialysis and clinical outcomes. Nephrol Dial Transplant 2009;24:3175-82.

5. Ledebo I, Kessler M, van Biesen W, et al. Initiation of dialysis opinions from an international survey: report on the Dialysis Opinion Symposium at the ERA-EDTA Congress, 18 September 2000, Nice. Nephrol Dial Transplant 2001;16:1132-8.

6. National Kidney Foundation. NKF-K/DOQI clinical practice guidelines for hemodialysis adequacy: update 2000. Am J Kidney Dis 2001;37(Suppl 1):S7-64.

7. Churchill DN, Blake PG, Jindal KK, et al. Clinical practice guidelines for initiation of dialysis. J Am Soc Nephrol 1999; 10(Suppl 13):S287-321.

8. Churchill DN. An evidence-based approach to earlier initiation of dialysis. Am J Kidney Dis 1997;30:899-906.

9. Bonomini V, Feletti C, Scolari MP, et al. Benefits of early initiation of dialysis. Kidney Int Suppl 1985;17:S57-9.

10. National Kidney Foundation. KDOQI clinical practice guidelines and clinical practice recommendations for 2006 updates: hemodialysis adequacy, peritoneal dialysis adequacy and vascular access. Am J Kidney Dis 2006;48(Suppl 1):S1-322.

11. Traynor JP, Simpson K, Geddes CC, et al. Early initiation of dialysis fails to prolong survival in patients with end-stage renal failure. J Am Soc Nephrol 2002;13:2125-32.

12. Beddhu S, Samore MH, Roberts MS, et al. Impact of timing of initiation of dialysis on mortality. J Am Soc Nephrol 2003;14: 2305-12.

13. Kazmi WH, Gilbertson DT, Obrador GT, et al. Effect of comorbidity on the increased mortality associated with early initiation 
of dialysis. Am J Kidney Dis 2005;46:887-96.

14. Cooper BA, Branley P, Bulfone L, et al. A randomized, controlled trial of early versus late initiation of dialysis. $N$ Engl J Med 2010;363:609-19.

15. Canadian Institute for Health Information. Treatment of endstage organ failure in Canada, 1999 to 2008 - CORR 2010 annual report. Ottawa $(\mathrm{ON})$ : The Institute; 2010. Available: http://secure.cihi.ca/cihiweb/products/corr_annual_report_2010 _e.pdf (accessed 2010 May 1).

16. Levey AS, Greene T, Kusek JW, et al. A simplified equation to predict glomerular filtration rate from serum creatinine. $J \mathrm{Am}$ Soc Nephrol 2000;11:155A.

17. National Kidney Foundation. KDOQI clinical practice guidelines for chronic kidney disease: evaluation, classification, and stratification. Am J Kidney Dis 2002;39(Suppl 1):S1-266.

18. Hemmelgarn BR, Manns BJ, Quan H, et al. Adapting the Charlson Comorbidity Index for use in patients with ESRD. Am J Kidney Dis 2003;42:125-32.

19. Korevaar JC, Jansen MA, Dekker FW, et al. When to initiate dialysis: effect of proposed US guidelines on survival. Lancet 2001;358:1046-50.

20. Tattersall J. Is it really better to start dialysis as late as possible? Nephrol Dial Transplant 2009;24:2972-4.

21. Murtagh FE, Marsh JE, Donohoe P, et al. Dialysis or not? A comparative survival study of patients over 75 years with chronic kidney disease stage 5. Nephrol Dial Transplant 2007; 22:1955-62.

22. Kausz AT, Obrador GT, Arora P, et al. Late initiation of dialysis among women and ethnic minorities in the United States. $J$ Am Soc Nephrol 2000;11:2351-7.

23. Shariff SZ, Cuerden MS, Jain AK, et al. The secret of immortal time bias in epidemiologic studies. J Am Soc Nephrol 2008;19: 841-3.

24. Grootendorst DC, Michels WM, Richardson JD, et al. The MDRD formula does not reflect GFR in ESRD patients. Nephrol Dial Transplant 2010 Nov. 4 [Epub ahead of print].

25. Parekh RS, Plantinga LC, Kao WH, et al. The association of sudden cardiac death with inflammation and other traditional risk factors. Kidney Int 2008;74:1335-42.

26. Selby NM, McIntyre CW. The acute cardiac effects of dialysis. Semin Dial 2007;20:220-8.

27. Herzog CA. Can we prevent sudden cardiac death in dialysis patients? Clin J Am Soc Nephrol 2007;2:410-2.

28. McIntyre CW, Stunning M, Ischemia HD, et al. Effects of hemodialysis on cardiac function. Kidney Int 2009;76:371-5.

29. Bleyer AJ, Russell GB, Satko SG. Sudden and cardiac death rates in hemodialysis patients. Kidney Int 1999;55:1553-9.

30. Hothi DK, Rees L, Marek J, et al. Pediatric myocardial stunning underscores the cardiac toxicity of conventional hemodialysis treatments. Clin J Am Soc Nephrol 2009;4:790-7.

31. Carson RC, Juszczak M, Davenport A, et al. Is maximum conservative management an equivalent treatment option to dialysis for elderly patients with significant comorbid disease? Clin J Am Soc Nephrol 2009;4:1611-9.

32. Korevaar JC, Jansen MA, Dekker FW, et al. Evaluation of DOQI guidelines: early start of dialysis treatment is not associated with better health-related quality of life. National Kidney Foundation-Dialysis Outcomes Quality Initiative. Am J Kidney Dis 2002;39:108-15.

33. Jassal SV, Chiu E, Hladunewich M. Loss of independence in patients starting dialysis at 80 years of age or older. $N$ Engl J Med 2009;361:1612-3.

34. Di Micco L, Torraca S, Pota A, et al. Setting dialysis start at 6.0 $\mathrm{ml} / \mathrm{min} / 1.73 \mathrm{~m}^{2}$ eGFR - a study on safety, quality of life and economic impact. Nephrol Dial Transplant 2009;24:3434-40.

35. Canadian Institute of Health Information. Data quality study on the Canadian Organ Replacement Register. Ottawa (ON): The Institute; 2009.

Affiliations: From the Division of Nephrology (Clark, Moist), Department of Medicine, and the Department of Epidemiology and Biostatistics (Sontrop, Macnab, Moist), University of Western Ontario, London Ont.; the Canadian Organ Replacement Register (Na), Canadian Institute for Health Information, Toronto Ont.; Dorn Research Institute
(Rosansky), William Jennings Bryan Dorn VA Hospital, Columbia, USA; Arnold School of Public Health (Rosansky, Jackson), University of South Carolina, Columbia, USA; David Geffen School of Medicine (Glassock), University of California, Los Angeles, Los Angeles, USA; and the Division of Kidney, Urologic and Hematologic Diseases (Eggers), National Institute of Diabetes and Digestive and Kidney Diseases, Bethesda, USA

Contributors: William Clark, Stephen Rosansky, Jessica Sontrop, Jennifer Macnab, Richard Glassock, Paul Eggers, Kirby Jackson and Louise Moist contributed to the concept and design of the study and interpretation of the results. Yingbo Na and Louise Moist contributed to acquisition of the data. Yingbo Na performed the data analyses and contributed to the interpretation of the results. William Clark, Stephen Rosansky, Jessica Sontrop and Jennifer Macnab drafted the article. All of the authors revised the manuscript critically for important intellectual content and approved the final version submitted for publication.

Funding: Funding for this study was provided by a grant to William Clark from the Program in Experimental Medicine (RO5 22A04), Department of Medicine, University of Western Ontario, London, Ont.

Acknowledgement: The authors thank the Canadian Organ Replacement Register for facilitating this study.

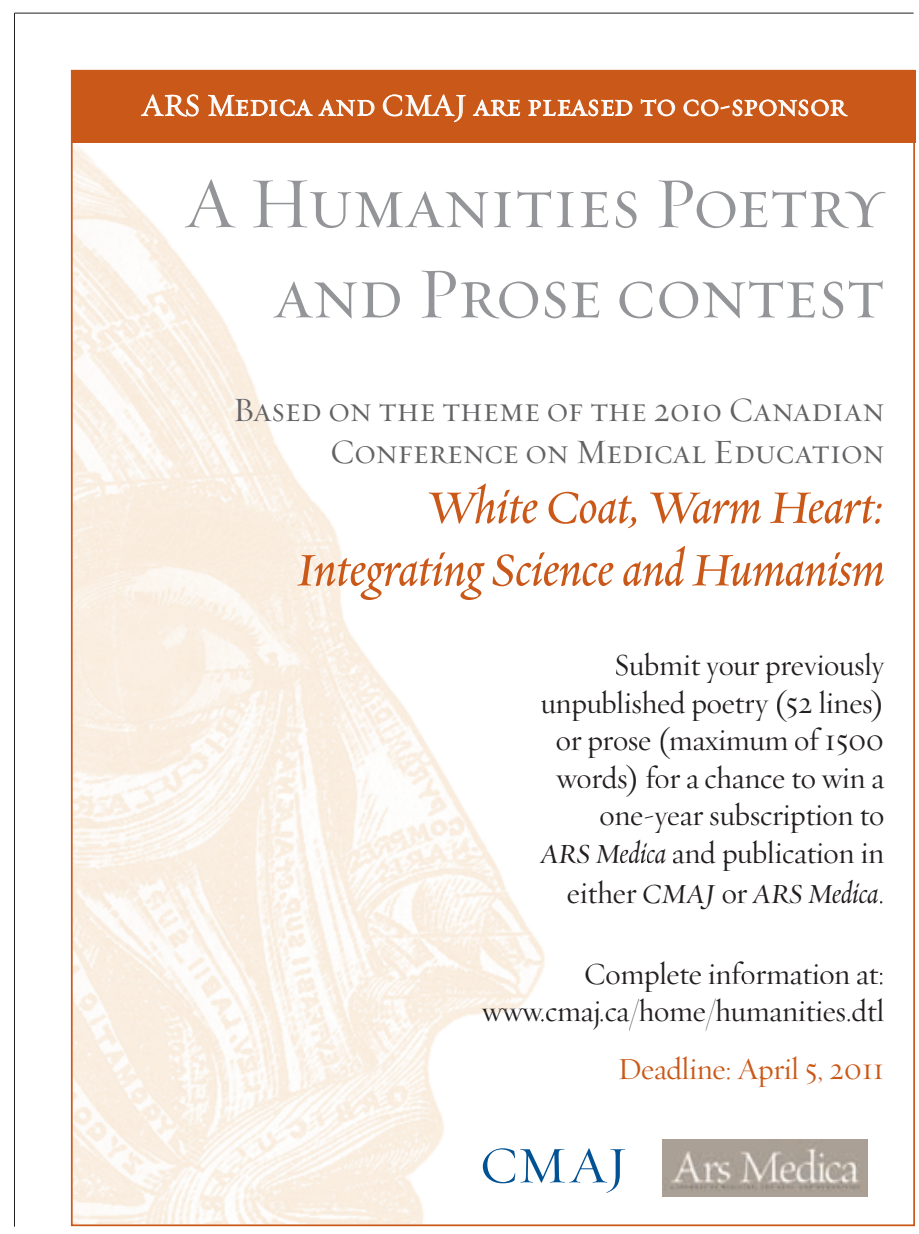

